\title{
Modelagem Matemática: Reflexões sobre a primeira experiência vivida.
}

\section{Samuel Francisco Huf} samuelfhuf@gmail.com $000-0002-3267-4152$ Universidade Estadual do Centro-Oeste, Guarapuava, Paraná, Brasil.

Dionísio Burak

dioburak@yahoo.com.br

Universidade Estadual do Centro-Oeste,

Guarapuava, Paraná, Brasil.
RESUMO

Este artigo apresenta o relato de uma experiência realizada com uma atividade de Modelagem Matemática na Educação Matemática, desenvolvida baseando-se nas novas tendências para o ensino e aprendizagem de matemática. A questão principal é: O que se mostra em uma atividade de Modelagem em relação à participação dos estudantes e do professor? Este artigo tem como objetivo descrever e analisar a atividade de Modelagem Matemática, no contexto do tema "água", sob o ponto de vista do professor e dos estudantes em uma primeira experiência. Por meio dessa primeira experiência, ainda com lacunas, foi possível constatar diferença considerável entre a prática educativa utilizando a Modelagem e a prática usual de ensino. A saída da zona de conforto do professor mostra que é possível a formação de um estudante mais crítico e mais preparado.

PALAVRAS-CHAVE: Modelagem Matemática. Educação Básica. Ensino e Aprendizagem. 


\section{INTRODUÇÃO}

Artigos 0 presente trabalho, ancorado nos pressupostos da Modelagem Matemática na Educação Matemática ${ }^{1}$, tem como tema a Coleta e o Tratamento de água. Descreve o desenvolvimento de uma prática em sala de aula, a interação, a participação e a produção dos estudantes de um colégio público do interior do estado do Paraná, no município de Cantagalo. Trata-se de uma experiência nessa tendência metodológica em que se buscou responder: 0 que se mostra em uma atividade de Modelagem Matemática em relação à participação dos estudantes e do professor? E como objetivo geral, destaca-se a descrição e análise de uma atividade de Modelagem como uma primeira experiência do professor e dos estudantes.

Quando se fala em matemática, a primeira impressão que a maioria dos estudantes têm é a de ser uma matéria "penosa" e difícil, que enfrenta, enfrentou ou enfrentará na vida escolar. Ao perguntar às crianças, mesmo aquelas que ainda não estão na escola, se gostam desta disciplina, a maioria afirmará que não, isso em decorrência, em parte, das influências de membros da família que estudam ou estudaram. Como aponta Rodrigues: "[...] a matemática tem sido apontada como a disciplina que mais suscita dúvidas e questionamentos dentro do contexto escolar, provocando desde a indiferença por parte dos alunos até traumas pessoais". (RODRIGUES, 2001, p.10).

Para Ponte (1994, p.26), uma das principais razões do insucesso na disciplina Matemática, segundo os alunos, é, por essa ser, de difícil compreensão. Em muitos casos os professores não a explicam muito bem e, também, não a tornam interessante, pois "não percebem para que serve nem porque são obrigados a estudá-la". Pode-se destacar ainda, que os estudantes estão se referindo ao ensino da forma tradicional: teoria, exemplos resolvidos e uma lista de exercícios a resolver.

Com a constatação de Ponte e diante da vivência do professor em sala de aula, cabe a esse o desafio de buscar novas formas e metodologias de se trabalhar, com o intuito de atingir e atender aos anseios dos estudantes, resgatando o gosto destes por estudar e compreender a matemática. Ausubel (2003, p.15) reforça que "Os seres humanos têm tendência a trabalhar mais e sentem-se muito mais motivados quando as actividades de aprendizagem que iniciam fazem sentido, em vez de não o fazerem".

Outro fator que reforça nossa opção por realizar essa experiências, é o fracasso escolar na disciplina de matemática no Brasil, apontado por várias pesquisas, dentre elas, uma realizada em 2012, pelo Programa de Avaliação Internacional de Estudantes (PISA) ${ }^{2}$, que avaliou o desempenho de estudantes em matemática. Dos sessenta países participantes do PISA, os resultados apontaram o Brasil em quinquagésima oitava posição, ou seja, acima de apenas dois países.

Além disso, segundo a Secretaria Estadual de Educação do Paraná $\left(\mathrm{SEED}^{3}\right)$, o último PISA, realizado em maio de 2015, priorizou avaliar situações reais da vida e abrangeu uma avaliação adicional dos estudantes em educação financeira e 
resolução colaborativa de problemas, com o objetivo de aferir como os estudantes lidam com seu dinheiro e como resolvem situações do cotidiano.

Este trabalho não tem a pretensão de se constituir em uma pesquisa, mas busca descrever e analisar as percepções dos envolvidos durante a realização da experiência, professor e estudantes. Essa experiência se justifica pela necessidade de mudança na forma de se ensinar e aprender Matemática. Ao encontro deste objetivo, situa-se a Modelagem Matemática como uma das tendências metodológicas, que segundo Burak (1992, p.62), "constitui-se em um conjunto de procedimentos cujo objetivo é construir um paralelo para tentar explicar, matematicamente, os fenômenos presentes no cotidiano do ser humano, ajudando-o a fazer predições e a tomar decisões".

\section{A MODELAGEM MATEMÁTICA NO CONTEXTO ESCOLAR}

A Modelagem Matemática atualmente vem se consolidando no âmbito da Educação, com avanços significativos do processo de ensino e aprendizagem quando comparada ao ensino de Matemática da forma tradicional. Com a Modelagem, o estudante vê sentido e significado naquilo que estuda, em função da satisfação pessoal em suprir necessidades de seu interesse, e é esse interesse que dá início à formação de atitudes positivas em relação à Matemática (BURAK; MARTINS, 2015).

Para Almeida e Dias (2004, p.25) a Modelagem pode "proporcionar aos alunos oportunidades de identificar e estudar situações-problema de sua realidade, despertando maior interesse e desenvolvendo um conhecimento mais crítico e reflexivo em relação aos conteúdos matemáticos".

Embora, ciente das várias concepções de Modelagem Matemática, assumimos para a realização dessa experiência a proposta por Burak, pois é fundada na perspectiva da Educação Matemática, além dos pressupostos das Ciências Sociais e Humanas e na epistemologia do conhecimento complexo. Prioriza a Educação Básica e articula a Matemática e a Educação, trabalhando a partir de temas de interesse dos estudantes, proporcionando a essa metodologia, características inter e transdisciplinares.

Burak (1998, 2004, 2010) sugere que a modelagem, para fins de encaminhamento didático, se desenvolva em cinco etapas norteadoras, sendo: escolha do tema; pesquisa exploratória; levantamento dos problemas; resolução dos problemas e desenvolvimento dos conteúdos matemáticos no contexto do tema; e análise crítica das soluções.

A escolha do tema caracteriza-se por ser um momento no qual os estudantes, e até mesmo o professor, sugerem e opinam sobre temas do interesse comum, que pode ser dos mais variados, não necessitando, inicialmente, ter ligação direta com conteúdo matemático. Ressalte-se que a decisão final pela escolha do tema é sempre dos estudantes.

Na pesquisa exploratória a partir do tema, os participantes são instigados a procurarem materiais e subsídios teóricos das mais variadas formas, desde pesquisa bibliográfica até trabalho de campo. Nesta etapa, Klüber e Burak (2008, p.21) destacam que "as questões levantadas previamente pelo grupo e a adição 
de novas situações levam a um comportamento mais atento, mais sensível, mais crítico, que são atributos desejáveis em um pesquisador".

$\mathrm{Na}$ etapa do levantamento dos problemas, com os materiais coletados nas pesquisas, os estudantes são motivados a conjecturar em relação à matemática para a elaboração de problemas, desde os mais simples até os mais complexos. Klüber e Burak $(2008$, p.21) apontam que isso deve ocorrer "[...] com a ajuda do professor, que não se isenta do processo, mas se torna o 'mediador' das atividades".

Para a Resolução dos problemas e o desenvolvimento do conteúdo matemático no contexto do tema, são buscados o auxílio dos conteúdos matemáticos que passam a ter sentido e significado para os estudantes.

A análise critica das soluções é destacada por Klüber e Burak (2008) como sendo uma etapa marcada pela criticidade em relação à viabilidade e a adequação das soluções apresentadas, que podem estar logicamente e matematicamente corretas, mas serem inviáveis à situação na prática. Etapa esta que "[...] podem ensejar a melhoria das decisões e ações, contribuindo, dessa maneira, para a formação de cidadãos participativos, que auxiliem na transformação da comunidade em que participam" (KLÜBER; BURAK, 2008, p.22).

\section{METODOLOGIA E DESENVOLVIMENTO DA ATIVIDADE DE MODELAGEM MATEMÁTICA}

Optamos por uma investigação de natureza qualitativa que, segundo Bogdan e Biklen (1994, p.17) tem um caráter flexível que "Permite aos sujeitos responderem de acordo com a sua perspectiva pessoal, em vez de terem de se moldar a questões previamente elaboradas". Os dados empíricos foram coletados e são constituídos pelas produções escritas dos estudantes, fotos e gravações durante a realização das atividades. $O$ tratamento e análise dos dados seguiram os pressupostos de Bogdan e Biklen (1994).

Inicialmente foi perguntado aos estudantes se estes já tiveram, em algum momento de sua trajetória escolar, contato com atividades de Modelagem. Questionados pelo professor se sabiam o significado do termo, para identificar a ideia e o conhecimento deles em relação ao assunto. Evidenciou-se que, do ponto de vista dos estudantes, a Modelagem era um termo novo, ainda desconhecido. Optou-se, então, por fazer uma breve fala expositiva para situá-los sobre o assunto e compreenderem os encaminhamentos em uma atividade nessa perspectiva.

Destaca-se que Modelagem Matemática é uma das tendências em Educação Matemática bastante discutida nas últimas décadas e defendida por vários pesquisadores, como uma forte possibilidade de superar a forma de ensino predominante e tornar o ensino e aprendizagem da Matemática mais efetivo.

Por ser uma das primeiras experiências do professor/autor com Modelagem, optou-se por trabalhar somente com um tema, que partisse do interesse da turma. $\mathrm{Na}$ primeira aula, após a divisão dos grupos por afinidade, os estudantes apresentaram e discutiram alguns temas, procurando o que trouxesse maior interesse para o objetivo comum. Destacou-se o tema "água" por ser o problema que a cidade, sede da escola, vinha enfrentando nos últimos dias e, defendido 
pelos estudantes como o bem mais precioso, pois, sem água não há vida no planeta.

As discussões em torno desse tema nos levaram a recorrer ao auxílio de outras áreas do conhecimento além da Matemática. Buscamos na área da Química conhecer os componentes da água e os materiais utilizados no tratamento; na área da Física o processo de captação e de distribuição da água; no campo da Ciência Ambiental foram contempladas discussões quanto à conservação e preservação das nascentes e dos rios e o resultado dessa preservação para a continuidade da vida no planeta. Isso evidencia uma perspectiva temática que segundo Morin (2015) possui caráter interdisciplinar. Interdisciplinaridade esta, que dificilmente é tratada em aulas de Matemática que seguem a forma tradicional.

Na sequência os estudantes tiveram o laboratório de informática reservado com o objetivo de pesquisar sobre o tema. A partir de pesquisas no site da Companhia de Saneamento do Paraná - Sanepar, os estudantes conheceram os procedimentos realizados desde a captação, passando pelo tratamento, até a distribuição da água destinada ao consumo, resumindo-se no esquema da Figura 1. No site encontra-se o detalhamento e a descrição do que consiste cada etapa.

Figura 1 - Captação e fases do Tratamento da água.

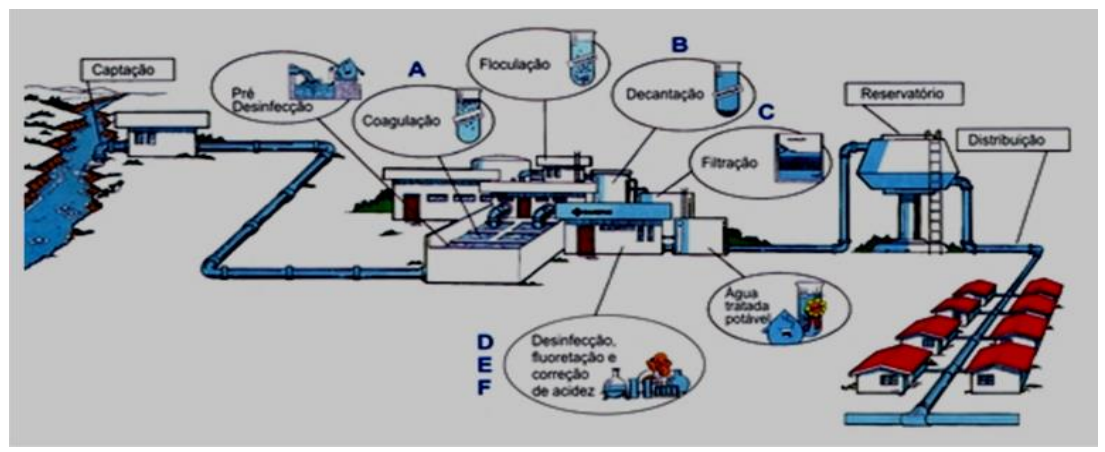

(Fonte: Companhia de Saneamento do Paraná - Sanepar.)

Após a pesquisa nos sites, ainda nessa etapa, nasceu o interesse dos estudantes em visitar uma estação de tratamento de água. Com o apoio da direção, da equipe pedagógica do colégio e da autorização dos pais, o professor autor incumbiu-se de entrar em contato com a Sanepar para verificar sobre a possibilidade da visita. Em conversa com o atendente foi argumentado que a visita devia ser autorizada pela sede da companhia. Encaminhado o ofício pela direção, foi concedida a autorização. Entretanto, a central de tratamento se localiza na cidade vizinha de Virmond-Pr, pois, segundo o técnico, o abastecimento da cidade de Cantagalo-Pr, se dá por meio de poços artesianos, no qual os processos de coleta e tratamento são mais simples.

A direção da escola conseguiu o transporte junto à prefeitura da cidade e a Sanepar disponibilizou um técnico para acompanhar e explicar todo o processo de tratamento, conforme Figura 2:

Figura 2 - Visita a central de tratamento de água. À esquerda, o técnico da Sanepar explicando as etapas do tratamento; à direita imagem da central com o laboratório onde ocorre análise de qualidade da água. 


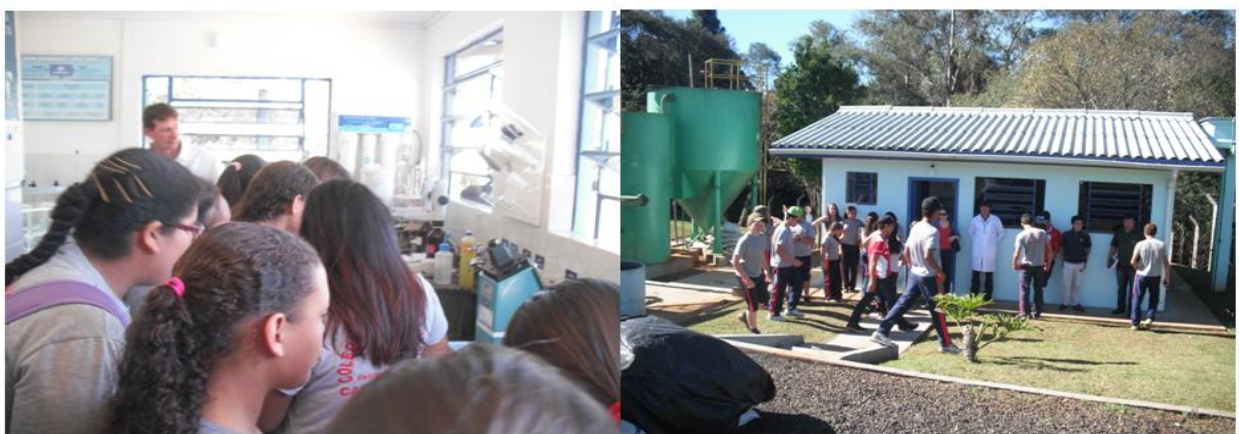

(Fonte: O autor 2014)

Foram coletados e anotados os dados relativos à captação, tratamento e distribuição da água durante a visita. Em sala de aula, os grupos buscaram levantar os problemas provenientes dos dados e informações coletadas nos sites e durante na visita. Em discussões sobre o que foi pesquisado e o observado em campo, os quatro grupos envolvidos apontaram que, mesmo sendo em dimensão menor, todas as etapas do tratamento encontradas em pesquisa no site da Sanepar são constatadas na central visitada. Nas discussões, os estudantes destacam e transcrevem algumas anotações que ouviram do técnico que os acompanhou, conforme Figura a seguir.

Figura 3 - Transcrito dos estudantes.
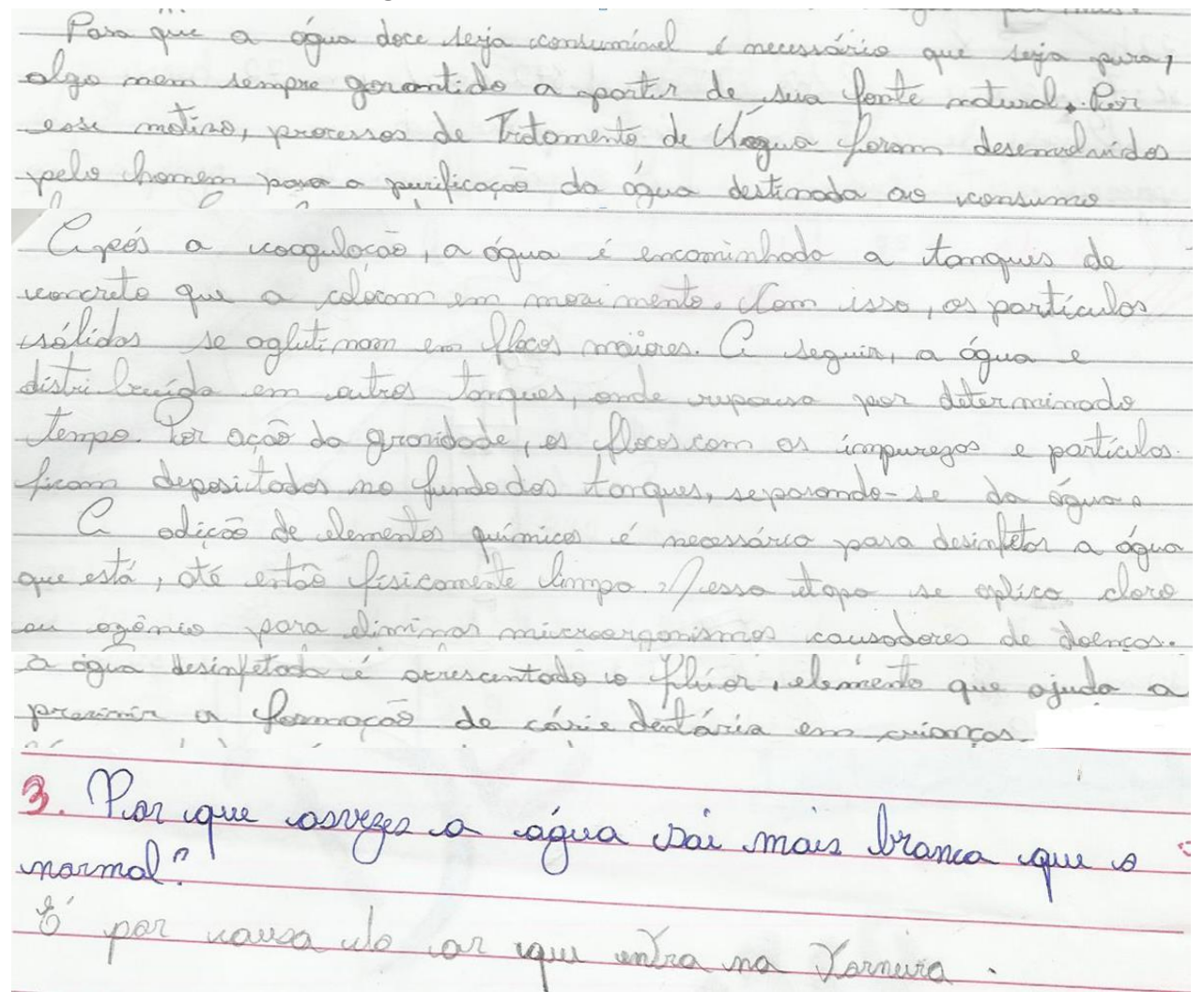

(Fonte: Anotações dos estudantes)

Como pode ser observado nas figuras acima, muitos transcritos dos alunos não têm, inicialmente, relação direta com a matemática, mas são conhecimentos válidos adquiridos e que se constituem como significativos para a experiência. Por 
exemplo, a questão referindo-se à cor da água, que às vezes quando ligada a torneira sai branca, segundo o técnico trata-se de um mito, no qual a população, de modo geral, acredita ser grande concentração de cloro e que, na verdade, isso ocorre devido à entrada de ar na tubulação. Um ocorrido na Sanepar, destacado pelo técnico, esclarece o fato: Certo dia uma senhora preocupada de estar ingerindo a água com muito cloro, coleta uma amostra da água e vai a Sanepar para fazer uma reclamação, explica à atendente o caso e diz que trouxe uma amostra, quando tira da mochila o litro com água, esta estava límpida e incolor. Isso ocorreu porque, ao ficar a água parada, esta se separou do ar.

Dentre os problemas apresentados pelos grupos, pela limitação no número de páginas de um artigo, somente três estão apresentados e discutidos, sendo o primeiro:

Figura 4 - Problema apresentado pelo Grupo 1

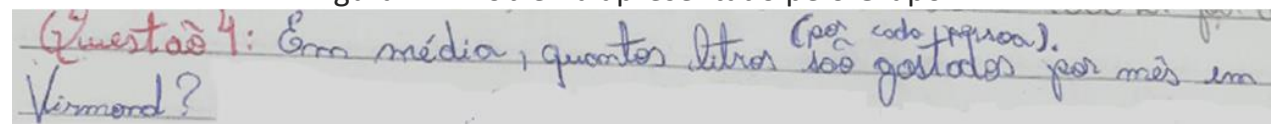

(Fonte: Anotações dos estudantes)

Para determinar esta quantidade, os estudantes foram indagados sobre quais os dados necessários para a solução do problema proposto. As respostas apontam como dados importantes para a solução: o volume de água captado, dado este, contido nas anotações dos estudantes no dia da visita; e a população da cidade que foi pesquisada na internet:

Figura 5 - Anotações do Grupo 1

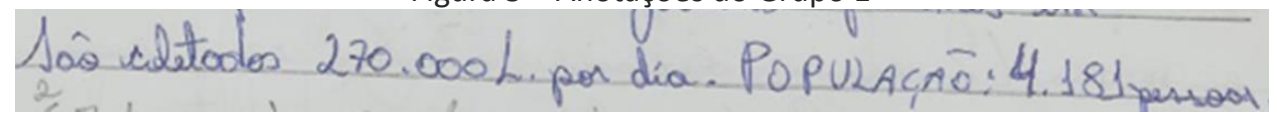

(Fonte: Anotações dos estudantes)

Com esses dados o grupo apresentou a resolução do problema, utilizando as operações de divisão e multiplicação:

Figura 6 - Resolução apresentada pelo Grupo 1

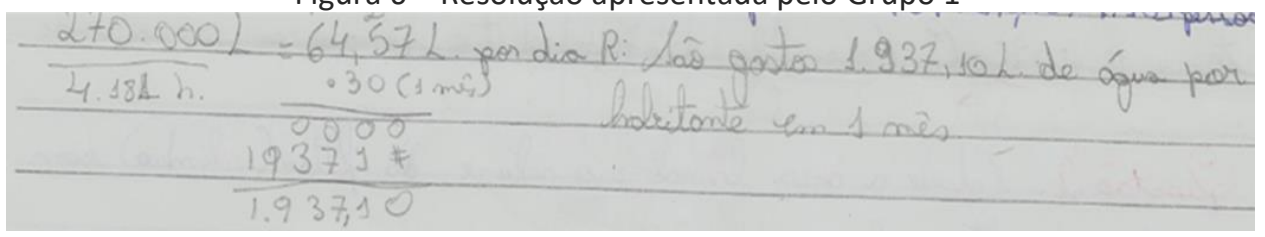

(Fonte: Anotações dos estudantes)

Pode-se observar nos procedimentos utilizados no grupo, os quais trouxeram o significado de cada valor e unidade utilizada nas operações, representado: L= litros; $h$ = habitantes; o resultado da primeira divisão é destacado, sendo, número de litros gastos por dia; mostra, ainda, que o número 30 significa o consumo em um mês e traz a resposta final do problema. A divisão, segundo eles, seria trabalhosa, então foi feita na calculadora, já a multiplicação foi realizada manualmente.

O problema apresentado pelo Grupo 1 despertou o interesse do Grupo 2 e vivenciou-se uma interação a partir das discussões e trocas de ideias em relação 
ao consumo de água entre as cidades de Cantagalo e Virmond (Figura7). Os diálogos entre os grupos mostram e ratificam a interação entre seus integrantes, uma característica da atividade de modelagem matemática.

Figura 7 - Problema apresentado pelo Grupo 2

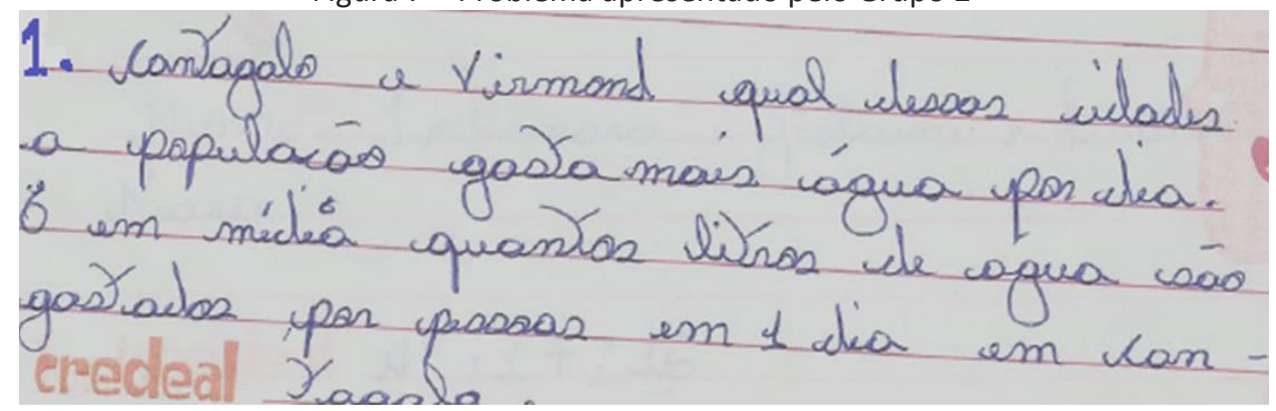

(Fonte: Anotações dos estudantes)

$\mathrm{Na}$ resolução do problema o Grupo2 não apresenta de forma clara os procedimentos utilizados, como o grupo anterior: os cálculos, o significado de cada valor e a natureza das unidades utilizadas, destacam apenas de forma oral que, ao se referir à população, pretendiam simplesmente estimar uma média de água gasta por habitantes de cada cidade. Para isso, tomando os valores encontrados na resolução do Grupo 2, o município que tem o maior consumo de água por habitante é Cantagalo.

Figura 8 - Resolução apresentada pelo Grupo 2

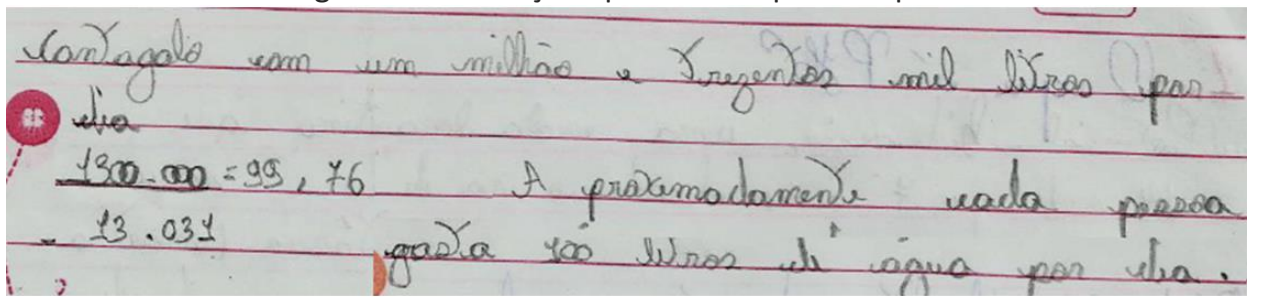

(Fonte: Anotações dos estudantes)

Na etapa da análise crítica da(s) solução (ões), os estudantes foram indagados quanto à confiabilidade e aceitação das respostas e dos resultados obtidos nas atividades. Dessa forma, em relação ao consumo de água, destacam que a população encontrada na pesquisa compreendia a população total de cada município. Considerando que a população total do município compreende a população urbana e a rural, e que em parte da área rural, a água não é fornecida pela Sanepar, isso faz com que o consumo médio de água da população urbana seja maior, pois os habitantes atendidos pela Sanepar são menos que a população total do município. E também, há outras variáveis que devem ser consideradas como, por exemplo, a indústria em geral consome mais água quando comparada com uma residência.

As discussões em relação às aproximações de resultados obtidos de operações foi outro assunto discutido na análise crítica das soluções. Os estudantes trabalharam com uma calculadora em que o visor comporta dez dígitos e perceberam que o quociente da divisão de $270000 L / 4181 h$ apontou 64,57785219 litros por habitante. Esse quociente ensejou dúvidas sobre como representá-lo. Foi quando, então se deu a ação do professor, enquanto mediador, 
ponderando que há duas formas de apresentar os resultados que se enquadram nessa situação, por truncamento ou arredondamento.

No resultado de $64,57 \mathrm{~L}$ apresentado pelos estudantes, percebe-se que eles utilizaram o truncamento que, segundo Ruggiero e Lopes (1996), possibilita um maior número de erros que no arredondamento. Se o resultado apresentado seguisse os critérios de arredondamento, seria aproximadamente $64,58 \mathrm{~L}$ por habitante, ou seja, 1937,4 L por mês contra 1937,1 L, apresentando uma diferença de $300 \mathrm{ml}$ por habitante durante o mês. No entanto, ao referir-se ao total da população perfaz um total de 1254,3 L.

O Grupo3 teve como objetivo calcular quanto de chapa de ferro é necessário para a construção de um filtro com diâmetro e altura de 10 metros. Inicialmente identificaram a forma do filtro compreendendo ser um cilindro. De imediato não sabiam como proceder. Na Modelagem, o professor exercita a mediação, isto é, faz a ponte entre o conhecimento historicamente construído e o conhecimento dos estudantes e, então, eles foram orientados a pesquisarem em livros didáticos.

Durante a realização da pesquisa, os estudantes encontraram o conteúdo relacionado ao estudo de cilindros na unidade denominada Geometria Espacial. 0 fato de muitas vezes, o problema necessitar de conteúdos ainda não estudados vem ao encontro do que afirma Burak (2010), de que na Modelagem o ensino e a pesquisa são indissociáveis. Coube ao professor, na interação com os estudantes, discutir e relacionar os elementos de um cilindro, sendo as bases dois círculos com raio $(r)$ e a altura(h), elementos estes utilizados no cálculo da área lateral, área total e o volume.

Coube, ainda, ao professor esclarecer a classificação dos cilindros em retos e oblíquos. A propósito, as expressões matemáticas que fornecem as áreas laterais e totais, bem como o cálculo do volume de um cilindro reto, em vista do tempo de duração da experiência e da inexperiência do próprio professor, as fórmulas utilizadas foram às expressões matemáticas apresentada no livro.

No entanto, a partir da planificação do cilindro sugerida pelo professor, foi percebido pelos estudantes que a área lateral constituía-se de um retângulo, tal que um dos lados é o valor que representa o comprimento da circunferência (2.r.r) e o outro lado representa a altura(h) do cilindro. $\mathrm{E}$, que a medida da área total é obtida pela adição da medida da área lateral mais a soma das áreas das bases. Como apresentada na Figura 9 a seguir: 
Figura 9 - Resolução apresentada pelos estudantes do Grupo 3

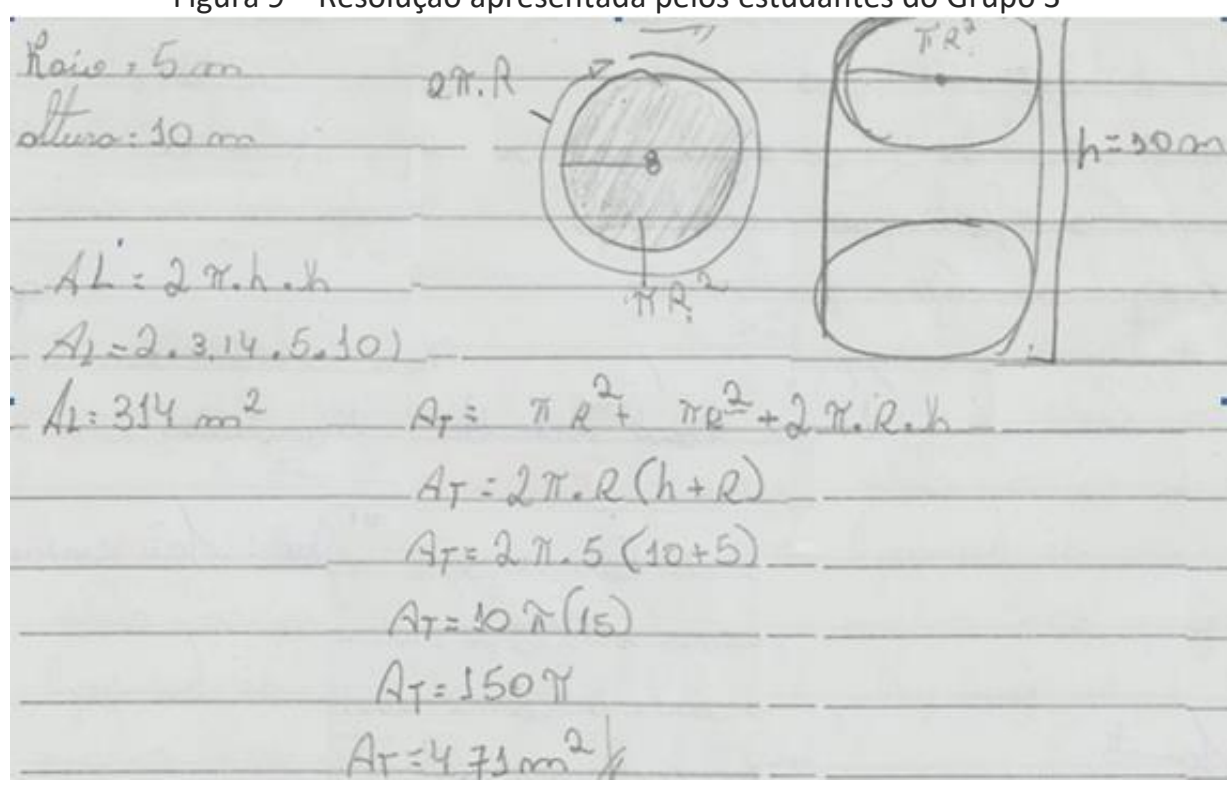

(Fonte: Anotações dos estudantes)

Pode-se observar que o Grupo3 apenas destaca o valor encontrado, não apresentando uma resposta mais elaborada, no entanto percebe-se pela Figura 9 que conduziram os cálculos deixando de relacionar o resultado com a quantidade de material necessário para a construção de um filtro. Os termos utilizados pelo grupo nos cálculos referem-se: $A L$ = área lateral; $A T$ = área total; $r$ = raio; $h=$ altura.

Quando questionados sobre a análise do resultado, os Grupos 3 e 4 interessados no problema, argumentaram ser o resultado encontrado um valor muito alto, mas ao compararem a altura e o diâmetro do filtro com uma parede da sala de aula, que tem 8 metros de comprimento por 3 metros de altura, compreenderam que o filtro era muito grande. Os estudantes refizeram os cálculos e não encontrando erro, aceitaram o resultado como verdadeiro.

Ainda que pelo tempo de realização da experiência não tivesse sido possível um tratamento mais aprofundado do conteúdo, foi discutida a possibilidade de um trabalho inicialmente experimental com o cilindro e foi possível o estudante observar que um cilindro se transforma em um retângulo e dois círculos das bases. No retângulo, os lados maior e menor têm respectivamente como medidas o comprimento da circunferência e a altura do cilindro. Nesse momento, passam a ter significado os conteúdos relativos à circunferência, raio, diâmetro e o número " $\pi$ ". Confirmando o apresentado por Burak (2010, p. 22):

\footnotetext{
Na resolução de um problema ou de uma situação-problema, os conteúdos matemáticos ganham importância e significado. As operações, as propriedades, e os diversos campos da matemática que se fazem presentes nessa etapa, sem dúvida atribuem significados aos conteúdos matemáticos.
}

Ao serem indagados sobre o número " $\pi$ ", os estudantes apenas apontaram ser um valor em torno de 3,14, usado na fórmula do cálculo da área de um círculo $\left(A_{c}=\pi \cdot r^{2}\right)$ e no comprimento de uma circunferência de círculo $\left(C_{c}=2 . \pi \cdot r\right)$. Sendo que, os conceitos de círculo e circunferência também se mostraram de forma 
confusa aos alunos, poucos sabiam diferenciar os significados, mas com os encaminhamentos adotados, perceberam que se estavam calculando a área então se referiam ao círculo e quando estavam determinando o comprimento, então estavam referindo-se a circunferência.

\section{REFLEXÕES SOBRE A EXPERIÊNCIA VIVIDA}

Essa primeira experiência vivida mostrou a importância de trilhar caminhos ainda não feitos, além de abrir o próprio caminho e foi o que inicialmente fizemos. Na sequência fazemos uma reflexão sobre a inserção dos participantes, professor e estudantes do 9ำ Ano do Ensino Fundamental, em atividades de Modelagem.

Em relação à participação e envolvimento dos estudantes, pôde-se perceber que desde o primeiro momento em que discutíamos sobre a possibilidade de praticarmos um trabalho diferente com a Matemática, um trabalho no qual os estudantes seriam protagonistas e, na medida em que foram dados os encaminhamentos, se mostraram interessados e participativos.

A percepção do professor quanto ao interesse e a participação dos estudantes foi verificada a partir de diferentes momentos e comportamentos: inicialmente, a partir de terem a oportunidade de discutirem, proporem e estudarem o tema que puderam escolher e que de alguma forma, era algo que estava afetando a todos, ou seja, a "água". Nessa ocasião a cidade estava enfrentando um problema com a falta de água e, então, os estudantes a consideraram, o bem mais precioso; outros comportamentos de interesse, participação e entusiasmo dos estudantes foram percebidos a partir de terem suas a reivindicação, de realizar uma visita de campo, atendida e de terem a oportunidade de conhecer, in loco, como se dão os processos de captação e tratamento da água; outros comportamentos percebido e manifestados pelas ações de participação, foi o diálogo e a interação propiciado por trabalharem em pequenos grupos e poderem discutir e interagir com os demais.

O envolvimento se deu também ao longo das etapas que constituem, segundo Burak (2010), as sugestões para o encaminhamento das atividades de Modelagem. Embora, a partir da pesquisa na internet já terem coletado elementos suficientes, os estudantes desejaram conhecer uma estação de tratamento para avaliar como essas coisas se davam no próprio local, isso corrobora com a afirmação da participação e envolvimento e interesse dos estudantes.

$\mathrm{Na}$ etapa que envolveu a coleta dos dados, junto a Sanepar, os questionamentos dos estudantes ao técnico que os acompanhou, com questões sobre como era feita a captação, o tratamento e a distribuição da água, mostrou a seriedade com que os participantes empreenderam essa tarefa. Outro ponto que corroborou com o envolvimento dos estudantes foi o apoio da Direção e da Equipe Pedagógica da escola no propósito de viabilizar a viagem para a cidade em que se localiza a Estação de Tratamento. Muito da participação se deveu por trabalharem com assunto de seu interesse, pela dinâmica que o trabalhado com a modelagem proporciona, isto é, o estudante é ativo, propõe, participa das decisões, pesquisa, levanta problemas de seu interesse e tem liberdade de utilizar estratégias distintas daquela contida nos livros textos.

Em relação aos conteúdos matemáticos envolvidos na resolução das questões propostas, podem ser colocados em dois momentos. 
No primeiro momento muitos dos conteúdos trabalhados caracterizam uma forma de revisão diferenciada de conteúdo dos anos anteriores. Isso foi percebido quando da utilização das operações elementares envolvendo o conjunto dos números racionais, sob a forma decimal e fracionária, na solução de problemas levantados pelos grupos. Consideramos uma revisão diferenciada, na medida em que foi utilizada na solução de problemas contextualizados, quando então estes conteúdos passaram a ter sentido e significado para os estudantes. Da mesma forma na utilização de conceitos geométricos de circunferência e círculo e alguns dos seus elementos, raio, corda, diâmetro, ângulo central entre outros. Embora, se constituam em elementos de revisão, eles diferenciavam-se na sua utilização, pela inserção em uma situação específica com contexto, o que conferiu significado a esses conteúdos.

O segundo momento foi constituído pela construção de conhecimentos novos. Um exemplo foi à proposta dos estudantes de calcular a quantidade de chapa de ferro para construção de um filtro com forma cilíndrica. Essa proposição ensejou nos estudantes a pesquisas sobre o assunto utilizando livros didáticos uma vez que não se constituía em conteúdo do 9ำ Ano. Formaram a ideia, o conceito de cilindro, conheceram e anotaram seus elementos e as expressões matemáticas que permitem o cálculo da área lateral e total. A planificação do cilindro possibilitou nos estudantes uma compreensão mais intuitiva. A situação vivida, o trabalho com conteúdos ainda não ensinados, foge das situações rotineiras da escola e confere uma nova perspectiva para a utilização do livro didático como uma fonte de pesquisa.

Nessa ocasião, nos deparamos com a questão da organização curricular da escola, uma vez que a solução do problema proposto pelo grupo envolvia a demanda de um conteúdo que não fazia parte do currículo do 9 Ano. Isso nos leva a refletir sobre a organização curricular como dificultador de uma metodologia mais aberta, como, a Modelagem Matemática na Educação Matemática. No entanto, mesmo com restrições de um currículo linear o trabalho do professor não precisa ser linear.

Em relação à participação docente na realização da experiência remete às reflexões sobre três percepções: o preparo; a disposição em superar obstáculos; e, em relação à perspectiva futura do trabalho com a Modelagem.

A primeira percepção em relação ao preparo inicial para o trabalho com uma nova metodologia mostrou que mesmo após as leituras sobre a Modelagem Matemática estas, ainda foram insuficientes, pois eram incipientes, e consistiram apenas aquelas conservadas do tempo da graduação. Tínhamos conhecimento de materiais impressos de muitos autores, que tratavam de diversas perspectivas, mas ainda não havíamos feito nenhuma experiência com a Modelagem. Quando sentimos necessidade de mudança em nossa prática, optamos por desenvolver uma atividade de Modelagem, pois é considerada uma das mais promissoras tendências em Educação Matemática e prevista, entre outras, no Currículo do Estado do Paraná.

Dentre as diversas perspectivas que tivemos contato por meio das leituras de artigos e livros percebemos maneiras distintas de entender e fazer a Modelagem Matemática. Embora, se considere outros autores também importantes, uma vez que todos, de alguma maneira, têm preocupações com o ensino de matemática, optamos por desenvolver nossa experiência a partir das orientações da concepção 
que pareceu a mais apropriada para a Educação Básica, a concepção de Modelagem Matemática na Educação Matemática de Burak $(1998,2004,2010)$. Considerou-se nessa decisão que o autor vivenciou os níveis da Educação Básica e trabalhou por mais de 25 anos e expressa preocupação explicita em relação ao ensino com vistas à aprendizagem dos estudantes.

A segunda percepção centra-se em relação à disposição de superar obstáculos. Na ocasião da realização da experiência, segundo a orientação adotada, juntamente com os estudantes do 9o Ano sobre o Tema "Água", em muitos momentos, sentimos alguma angústia por navegarmos solitariamente, sem interlocução, sem uma maior interação em vista das dificuldades de comunicação e a escassez de material mais atualizado. Dessa forma, uma reflexão sobre a experiência desenvolvida mostrou um preparo, ainda incipiente, pois, deixamos passar algumas oportunidades de encaminhar muitas das situações que se apresentaram de forma diferenciada no decorrer das atividades que, no entanto, foram abordadas de uma forma mais usual pela tradição e a cultura do ensino de Matemática.

Percebemos como a tradição e a cultura prevalece e conforma as maneiras, ainda usuais de ensinar Matemática na Educação Básica. Entretanto, mesmo enfrentando dificuldades, em outros momentos conseguimos estabelecer relações fortes com as etapas propostas da concepção assumida, conforme se percebe no texto. Na medida em que o trabalho se desenvolvia, nossa compreensão também mudava e para melhor. Compreendemos que somente se aprende fazer Modelagem, fazendo.

A terceira percepção constituiu-se em relação à perspectiva futura do trabalho com a Modelagem. Durante essa primeira experiência sentimos que faltava no momento, uma maior interlocução, maior vivência e um ambiente em que se pudesse discutir e aprofundar referências e fundamentos que sustentam a Modelagem Matemática na Educação Matemática. Na busca por maior interlocução, leituras e discussões, e interação mais abrangente com que estudava e pesquisava sobre a Modelagem, mantivemos contato e fomos convidados a participar do Grupo de Pesquisa e Ensino em Educação Matemática - GPEEM, no qual encontramos como participantes, professores da Licenciatura em Matemática e Pedagogia, professores da Educação Básica, estudantes da Graduação e de PósGraduação das Licenciaturas e Pedagogia que, me impulsionaram a buscar o aperfeiçoamento pessoal e profissional.

As reflexões com o coordenador, em relação à experiência vivida, deram a dimensão e o valor pedagógico da empreitada que nos propusemos assumir. Decidimos prestar a seleção para ingresso no Mestrado Profissional, e aceito após etapas e seleção, com um projeto que envolve a Modelagem.

\section{CONSIDERAÇÕES FINAIS}

O presente trabalho, a primeira experiência docente vivida, utilizando a Modelagem Matemática na Educação Matemática, mostra que muda fundamentalmente a dinâmica da sala de aula, pelo protagonismo que os 
estudantes exercem. As interações ocorridas intra e intergrupos mostraram nessa experiência, que os estudantes se constituem em sujeitos da construção do seu conhecimento, pois ao terem a oportunidade de serem ouvidos e atendidos em suas reivindicações, poderem escolher o tema de interesse para desenvolver a atividade, bem como, a oportunidade de buscar os dados sobre o tema utilizandose de sites, literatura, artigos e complementando com a pesquisa de campo, ainda como parte do fazer modelagem liberdade de conjeturar e criarem estratégias próprias na solução dos problemas em estudo, sem dúvida que a mediação pela Modelagem pode se constituir em uma prática diferenciada.

Na concepção de Modelagem assumida para este trabalho são os problemas ou as situações-problema que determinam os conteúdos a serem utilizado. Esse fato difere das situações do ensino de matemática na forma tradicional "no qual o conteúdo estabelecido no programa é que determina o tipo de problema a ser abordado" (BURAK; MARTINS, 2015, p.102). Com o exemplo dessa primeira experiência, foi possível admitir que na Modelagem Matemática um único tema pôde sugerir o estudo de conteúdos variados, abrangendo os distintos campos da matemática: números e operações, grandezas e medidas, tratamento da informação, geometria e álgebra. Isso também merece especial atenção, pois a atividade quando temática tem o potencial de ampliar as necessidades de conhecimentos e conteúdos não apenas da Matemática, mas também de outras áreas do conhecimento.

Nessa compreensão normalmente supera aqueles conhecimentos determinados por um currículo previsto para cada nível ou ano escolar. Esse fato merece atenção, pois durante o desenvolvimento das atividades houve ruptura com o currículo linear estabelecido para o 9ำ Ano. Ainda, outro fato constatado é o potencial integrador da Modelagem na Educação Matemática com outras áreas do conhecimento. Isso nos remete a um novo modo de se olhar para o ensino que supere a perspectiva disciplinar.

A experiência vivida evidenciou diferença substancial entre uma prática educativa utilizando a Modelagem e a prática usual de um ensino de Matemática centrado em memorização, problemas de livro texto e situações fictícias. A reflexão mostrou a inadequação da formação inicial do professor para o momento vivido no âmbito da escola. Além disso, percebemos e vivenciamos ainda que com muitas lacunas próprias de uma primeira experiência, o potencial educativo da Modelagem na Educação Matemática. No entanto, para o professor ter noção desse potencial, deve sair da acomodação e superar as dificuldades existentes: sejam no âmbito da formação inicial, nas concepções de conhecimento e as existentes no âmbito da organização do sistema escolar.

É importante, enquanto professores, estarmos dispostos a trilhar caminhos ainda não abertos, mas que com certeza, são potencialmente ricos e fundamentais para a formação dos estudantes, cidadãos desse século. 


\title{
MATHEMATICAL MODELING: REFLECTIONS ON THE FIRST EXPERIENCE.
}

\begin{abstract}
This paper presents an account of an experience conducted with a Mathematical Modeling activity in Mathematics Education, it was developed based on the new trends in teaching and learning of mathematics. The main question is: What is shown in a modeling activity in relation to the participation of students and teachers? This article aims to describe and analyze the mathematical modeling activity, in the context of the theme "water", from the teacher and students' point of view in their first experience. Through this first experience, even with gaps, it was possible to observe a considerable difference between the educational practice using the modeling and the usual practice. The output of the teacher's comfort zone shows that the formation of a more critical and more prepared student is possible for the present century.
\end{abstract}

KEYWORDS: Mathematical Modeling. Basic education. Teachingand Learning. 
1 Para evitar repetições utilizaremos a expressão Modelagem ou Modelagem Matemática significando Modelagem Matemática na Educação Matemática.

2 Programme for International Student Assessment (Pisa) - Programa Internacional de Avaliação de Estudantes.

3

Disponível

em:

http://matematica.seed.pr.gov.br/modules/noticias/article.php?storyid=951

Acessado 12/12/2015.

\section{REFERÊNCIAS}

ABNT NBR 5891:1977. Regras de arredondamento na numeração decimal. 1a . Ed., 1p., ANNT, 1977

ALMEIDA, L. M. W.; DIAS, M. R. Um estudo sobre o uso da Modelagem Matemática como estratégia de ensino e aprendizagem. Bolema: Boletim de Educação Matemática, Rio Claro, v. 17, n. 22, p. 19-35, 2004.

AUSUBEL, D. P. Aquisição e retenção de conhecimentos: uma perspectiva cognitiva. Lisboa: Plátano, 2003.

BOGDAN, R; BIKLEN, S. Investigação qualitativa em Educação: fundamentos, métodos e técnicas. Investigação qualitativa em educação. Portugal: Porto Editora, p. 15-80, 1994.

BURAK, D. Modelagem Matemática: ações e interações no processo de ensinoaprendizagem. 1992. Campinas: FE/UNICAMP, 1992. (Tese, Doutorado)

Modelagem Matemática sob um olhar de Educação Matemática e suas implicações para a construção do conhecimento matemático em sala de aula. Modelagem na Educação Matemática, v. 1, n. 1, p. 10-27, 2010.

BURAK, D.; ARAGÃO, R.M.R. de. Modelagem matemática e relações com a aprendizagem significativa. Editora CRV. 1.ed, Curitiba-Brasil. 2012.

BURAK, D; MARTINS, M. A. Modelagem Matemática nos anos iniciais da Educação Básica: uma discussão necessária. Revista Brasileira de Ensino de Ciência e Tecnologia, v. 8, n. 1, 2015.

KLÜBER, T. E; BURAK, D. Concepções de modelagem matemática: contribuições teóricas. Educação Matemática Pesquisa, v. 10, n. 1, 2008. 
MORIN, E. A Cabeça bem - feita: Reformar a reforma, reformar o pensamento. 22a ed. Rio de Janeiro: Bertrand, Brasil, 2015.

PONTE, J. P. Matemática: uma disciplina condenada ao insucesso. NOESIS, n. 32, p. 24-26, 1994.

RODRIGUES, R. N. Relações com o saber: um estudo sobre o sentido da matemática em uma escola pública. 2001. Tese de Doutorado-PUC, São Paulo.

RUGGIERO, M. A. G; LOPES, V. L. R. Cálculo Numérico - Aspectos Teóricos e Computacionais. 2. ed. Sao Paulo: Pearson Education (Makron Books), 1996. 406p.

SANEPAR. Sanepar Educando. Disponível em: http://educando.sanepar.com.br/category/ensinofundamental/\%C3\%A1gua/tratamento. Acessado em: 03/10/2014

SEED. No Brasil, 33 mil alunos farão provas para o 'ranking mundial de educação. Disponível em:

http://matematica.seed.pr.gov.br/modules/noticias/article.php?storyid=951 Acessado em: 12/12/2015.

Recebido: 2016-02-18

Aprovado: 2017-04-12

DOI: $10.3895 /$ rbect.v10n2.3766

Como citar: HUF, S. F.; BURAK, D. Modelagem Matemática: Reflexões sobre a primeira experiência vivida.

Revista Brasileira de Ensino de Ciência e Tecnologia, v. 10, n. 2, 2017. Disponível em:

<https://revistas.utfpr.edu.br/rbect/article/view/3766>. Acesso em: xxx.

Correspondência:

Direito autoral: Este artigo está licenciado sob os termos da Licença Creative Commons-Atribuição 4.0 Internacional.

\section{(c) (i)}

